\title{
Surface properties of monolithic zirconia after dental adjustment treatments and in vitro wear simulation
}

\author{
Verena Preis $^{a, *}$, Michael Schmalzbauer ${ }^{b}$, Dominique Bougeard ${ }^{b}$, \\ Sibylle Schneider-Feyrer ${ }^{a}$, Martin Rosentritt ${ }^{a}$ \\ ${ }^{a}$ Department of Prosthetic Dentistry, Regensburg University Medical Center, Regensburg, Germany \\ ${ }^{\mathrm{b}}$ Institute for Experimental and Applied Physics, University of Regensburg, Germany
}

\section{A R T I C L E I N F O}

Article history:

Received 6 May 2014

Received in revised form

8 August 2014

Accepted 15 August 2014

Keywords:

Monolithic zirconia

Adjustment

Polishing

Wear

Roughness

Phase transformation

\begin{abstract}
A B S T R A C T
Objectives: To investigate the surface properties (roughness, composition, phase transformation) of monolithic zirconia specimens after dental adjustment procedures (grinding, polishing) and wear simulation.

Methods: Zirconia specimens (Cercon base, Cercon ht, DeguDent, G; $n=10 /$ material) were successively sintered, ground, and polished with an intraoral polishing kit in a three-step procedure. Sintered zirconia specimens with high surface roughness served as a reference. For each treatment step, wear simulations with steatite plates $(d=10 \mathrm{~mm})$ as antagonists were conducted as well as surface roughness tests $\left(R_{\mathrm{a}}\right)$, EDX analysis, and X-ray diffraction (XRD) measurements. SEM pictures were taken, and data were statistically analyzed (one-way ANOVA, post hoc Bonferroni, $\alpha=0.05$ ).

Results: Grinding significantly $(p=0.000)$ increased the roughness of sintered zirconia up to values of $1.36 \pm 0.11 \mu \mathrm{m}\left(R_{\mathrm{a}}\right)$. Polishing significantly $(p=0.000)$ reduced $R_{\mathrm{a}}$. The lowest roughness value after the final polishing step was $0.20 \pm 0.03 \mu \mathrm{m}$. Wear testing resulted in a further slight decrease of $R_{\mathrm{a}}$. After the grinding procedure, SEM pictures showed deep grooves that were progressively smoothed by polishing. The EDX spectra showed that magnesium was transferred from steatite antagonists to zirconia by wear. In the XRDpatterns, monoclinic $(\mathrm{m})$ peaks were observed after grinding and polishing. The maximum intensity ratio between the $\mathrm{m}\left(\begin{array}{ll}1 & 1\end{array}-1\right)$ peak and the tetragonal $\mathrm{t}(111)$ peak decreased after the completion of all polishing steps. Wear did not induce phase transformation.

Conclusions: Adequate polishing reduced the roughness of ground zirconia. Wear had little influence on roughness and no influence on phase transformation.

Clinical significance: Careful polishing is recommended to keep surface roughness and phase transformation low.
\end{abstract}

(C) 2014 Elsevier Ltd. All rights reserved.

\footnotetext{
* Corresponding author at: Department of Prosthetic Dentistry, University Medical Center Regensburg, 93042 Regensburg, Germany. Tel.: +49 941944 6073; fax: +499419446171.

E-mail address: verena.preis@ukr.de (V. Preis). http://dx.doi.org/10.1016/j.jdent.2014.08.011 0300-5712/(C) 2014 Elsevier Ltd. All rights reserved.
} 


\section{Introduction}

Full-contour zirconia crowns and fixed partial dentures have become an alternative treatment option to commonly veneered zirconia-based restorations, particularly in less visible dental areas. Chairside adjustment of zirconia restorations is usually required to achieve optimal occlusal contact situations. Such surface manipulations include grinding, and this procedure results in the circumscribed loss of the glaze layer and surface smoothness. Subsequently, use of an intraoral polishing kit has become a well-established alternative method to re-glazing but this procedure is not consequently applied by all dentists. Over the subsequent clinical service time, zirconia surfaces become directly exposed to wear. Even without the application of any preceding adjustment procedure, thin glaze layers are known to become worn within the first six months after the insertion of the restoration, ${ }^{1}$ thus uncovering the zirconia surface.

Any adjustment procedure of zirconia surfaces may induce superficial modifications, damage, and phase transformation from the tetragonal $(t)$ to the monoclinic (m) phase. ${ }^{2-4}$ Such changes can negatively influence the mechanical properties of a zirconia restoration, for example, with regard to flexural strength, hardness, and elastic modulus. ${ }^{4-6}$ Furthermore, such changes can have detrimental consequences for the long-term behaviour of a restoration during clinical service. A high $\mathrm{t} \rightarrow \mathrm{m}$ transformation rate may decrease the mechanical stability over time because zirconia loses its toughening effect and resistance against crack propagation. ${ }^{7}$ Because surface roughness and damage are also known to influence the wear process, 8,9 different surface manipulations carried out by dentists may alter the wear performance of zirconia. Other investigations have already shown that the wear of material and antagonist of smoothly polished zirconia specimens is even less than that of veneering and glass ceramics.,10 Furthermore, the wear process itself can influence the surface roughness of zirconia, cause debris, and lead to phase transformation. Many studies have investigated zirconia surfaces manipulated by sandblasting or grinding for the adaption of inner zirconia surfaces or to increase bonding to the tooth. ${ }^{3,4,11,12}$ However, little is known about the consequences of occlusal surface modifications of zirconia by chairside adjustment procedures followed by wear simulation.

The hypothesis of this study was that surface roughness and phase transformation are influenced by dental adjustment procedures (grinding, polishing) and wear.

\section{Materials and methods}

\subsection{Specimen preparation}

Specimens (10 discs per material, diameter $20 \mathrm{~mm}$, thickness $1.5 \mathrm{~mm}$ ) were prepared from two different yttria-stabilized zirconia ceramics (Cercon ht, Cercon base, both by DeguDent, Hanau, G). The specimens were cut at the pre-sintered stage with a water-cooled diamond saw (Accutom 2, Struers, Willich, G) and then sintered (Cercon heat plus, DeguDent). Cercon base, a common zirconia material with low translucency, was sintered at $1350^{\circ} \mathrm{C}$ (hardness: $1454 \mathrm{HV} 10$, fracture toughness: $6.4 \mathrm{MPa} \mathrm{m}^{1 / 2}$ ). Cercon ht with higher translucency (ht) was sintered at $1500{ }^{\circ} \mathrm{C}$ (hardness: 1485 HV10, fracture toughness: $8.1 \mathrm{MPa} \mathrm{m}^{1 / 2}$ ). Two further specimens (Cercon base) that were additionally roughened with silicon carbide grinding paper (Buehler, Lake Bluff, USA) before sintering served as a sintered reference with high surface roughness because a potential influence of surface roughness on phase transformation was assumed.

To simulate clinical adjustment procedures carried out by dentists in clinical practice, specimens were subjected to different surface treatments after sintering. Zirconia ceramics were successively ground and polished in three steps. Grinding was done with a diamond bur (837LF FG 014, 27-76 $\mu \mathrm{m}$, Meisinger, Neuss, G) under standardized conditions (permanent water cooling, $1 \mathrm{~N}, 160,000 \mathrm{rpm}, 10 \mathrm{~s}$ ). To achieve a high-gloss surface of the ceramics, polishing consisted of the progressive use of a 3-step intraoral polishing set (CeraGlaze, P335, P3035, P30035, NTI, Kahla, G) in a definite procedure (2 N, $30 \mathrm{~s}$, step 1: 15,000 rpm, step 2: 10,0000 rpm, step 3: $5000 \mathrm{rpm}$ ) according to the instructions of the manufacturer. After each step of this process (sintering, grinding, and polishing step 1, step 2, step 3), two specimens of each material were kept at the obtained surface state for further investigation. One of the two specimens was subjected to wear simulation (ZM-3; SD Mechatronik Feldkirchen-Westerham, G) with steatite plates ( $d=10 \mathrm{~mm}$, CeramTec, Plochingen, $\mathrm{G}$ ) that served as antagonists. Loaded with $25 \mathrm{~N}$, circular movements with a travel path of $8 \mathrm{~mm}$ were conducted for 120,000 cycles at a velocity of $20 \mathrm{~mm} / \mathrm{s}$ and under water-cooling.

\subsection{Surface roughness}

After each step of the surface treatment and after wear simulation, surface roughness $R_{\mathrm{a}}$ (arithmetic average roughness) was determined perpendicularly to the grinding or polishing direction by means of a profilometric contact surface measurement device (Perthometer SP6, Feinprüf-Perthen, Mahr, Göttingen, G; 5 measurements per specimen; $\mathrm{LT}=1.7 \mathrm{~mm} / 0.25 \mathrm{~mm}$, velocity $0.1 \mathrm{~mm} / \mathrm{s}, 2 \mu \mathrm{m}$ diamond indenter).

\subsection{Scanning electron microscopy (SEM) and energy dispersive X-ray spectroscopy (EDX)}

SEM (working distance: $20.4 \mathrm{~mm}$; voltage: 5-10 keV; low vacuum; Quanta FEG 400, FEI Company, Hillsboro, USA) was used for qualitative surface evaluation. Surfaces were examined at magnifications between 500 and 30,000. Elemental composition was determined by EDX analysis (EDAX Genesis 2000, Ametek, Meerbusch, G) at a magnification of 1000. To determine the potential material transfer during wear simulation, we investigated both specimens and steatite antagonists.

\subsection{X-ray diffraction (XRD)}

XRD analysis (D5000 diffractometer, Siemens, Munich, G) by means of $\mathrm{Cu} \mathrm{K} \alpha_{1}$ radiation was conducted to examine the influence of different surface treatments and wear simulation on the phase composition and transformation of zirconia. 
The specimens were mounted into sample holders, and scans were conducted at $40 \mathrm{kV} / 40 \mathrm{~mA}$. Diffraction profiles were acquired in a range from $20^{\circ}$ to $38^{\circ}$ in a continuous $\theta / 2 \theta$ scan with a step size of $0.004^{\circ}$ and a counting time of $4.0 \mathrm{~s} / \mathrm{step}$. To get an optimal signal-to-noise-ratio, we repeated every single scan 5 times in the same measurement run and averaged all values. The results were plotted with QtiPlot A (ProIndep Serv S.r.l., Craiova, Romania). The identification of phases was based on the ICSD database (Inorganic Crystal Structure Database, FIZ Karlsruhe, G). The ratio of the maximum peak intensities of the monoclinic m (1 $11-1)$ and tetragonal t (1 111$)$ phases was used to compare the extent of phase transformation after different surface treatments. The absolute peak intensities of both phases showed variations in time that were related to the $\mathrm{X}$-ray cathode. The ratio of both diffraction peaks, however, was verified to be constant in time for all specimens. Finally, the full width at half maximum (FWHM) of the $t\left(\begin{array}{lll}1 & 1 & 1\end{array}\right)$ peak was extracted with Origin 8.1G (OriginLab Corporation, Northampton, USA).

Calculations and statistical analysis were carried out using IBM SPSS Statistics 21.0 (IBM, Armonk, NY, USA). Mean values and standard deviations (SD) were calculated and analyzed by means of one-way analysis of variance (ANOVA) and the Bonferroni multiple comparison test for post hoc analysis. The level of significance was set to $\alpha=0.05$. The expected statistical power for the chosen number of measurements $(n=5)$ per group was $97.7 \%$ (G*Power 3.1.3, University Kiel, Germany).

\section{Results}

\subsection{Surface roughness}

Surface roughness $R_{a}$ values (Fig. 1) showed statistically significant $(p=0.000)$ differences between the various groups. Grinding of the sintered surfaces significantly $(p=0.000)$ increased $R_{\mathrm{a}}$. High surface roughness was significantly ( $p=0.000$ ) reduced after the first polishing step for both zirconia

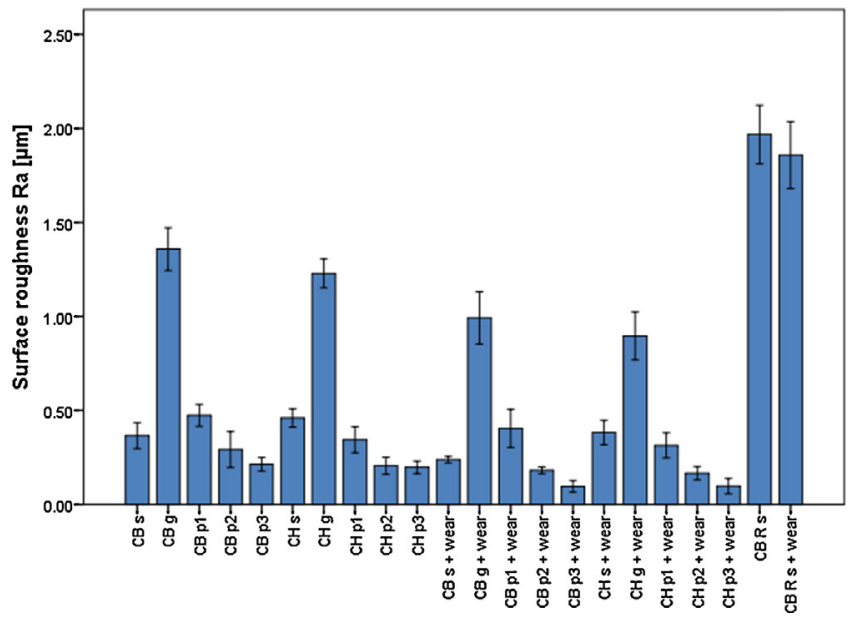

Fig. 1 - Surface roughness $R_{a}$ (mean, standard deviation) of the zirconia specimens (Cercon base: $\mathrm{CB}$, Cercon ht: $\mathrm{CH}$, Reference: $R$ ) with different surface treatments before and after wear testing: sintering (s), grinding (g), polishing step 1 (p1), step 2 (p2), step 3 (p3). materials. Roughness was further reduced by the subsequent polishing steps. However, step 1 and step 2 as well as step 2 and step 3 did not differ significantly $(p>0.05)$ in any material. Wear testing resulted in a further slight decrease in $R_{a}$, although this difference was only significant $(p=0.000)$ for the ground specimens of the two zirconia materials. In all other surface treatments, wear testing did not significantly reduce $(p>0.05)$ surface roughness. The reference group showed significantly ( $p=0.000$ ) higher $R_{\mathrm{a}}$ values than all other specimens, both before and after wear testing. When comparing the zirconia materials Cercon base and Cercon ht, specimens with the same surface treatment did not show any significant $(p>0.05)$ differences in roughness, neither before nor after wear testing.

\subsection{Scanning electron microscopy}

SEM images of both zirconia materials (Table 1) showed plain sintered surfaces with a fine-grained structure before wear testing. The surfaces showed some small imperfections and holes. Grinding made the surfaces appear rough and melted with deep grinding grooves, and grain boundaries widely disappeared. After the subsequent polishing steps, the surfaces were progressively smoothed, but some deep grinding grooves could not be entirely removed.
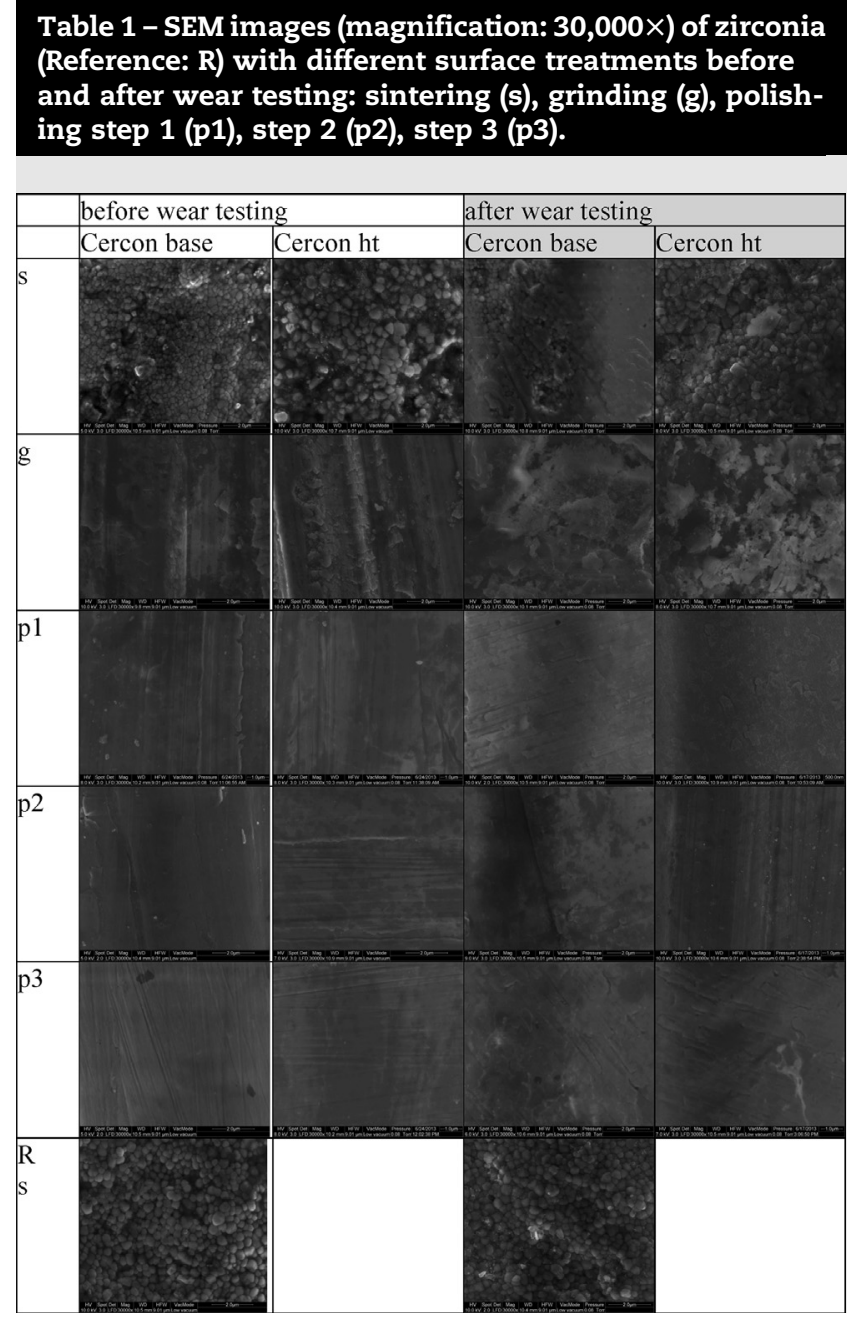
Table 2 - EDX elemental composition of steatite and zirconia (Cercon base, Cercon ht) before and after wear testing.

\begin{tabular}{|c|c|c|c|c|c|}
\hline Element (Wt\%) & Cercon base & Cercon ht & Cercon base + wear & Cercon ht + wear & Steatite \\
\hline $\mathrm{Zr}$ & $65.45-71.38$ & $67.70-70.54$ & $57.26-72.44$ & $61.38-73.28$ & 0 \\
\hline 0 & $18.94-24.04$ & $19.36-21.84$ & $18.37-30.17$ & $16.89-26.26$ & 58.40 \\
\hline Y & $6.28-7.94$ & $6.54-7.58$ & $5.87-8.88$ & $5.91-6.86$ & 0 \\
\hline $\mathrm{Si}$ & $0.84-1.17$ & $0.7-1.11$ & $0.5-2.65$ & $0.4-2.03$ & 24.36 \\
\hline $\mathrm{Hf}$ & $1.34-1.87$ & $1.21-2.08$ & $1.44-1.94$ & $1.02-1.68$ & 0 \\
\hline $\mathrm{Al}$ & $0.51-1.02$ & $0.49-0.69$ & $0.1-1.01$ & $0.63-0.96$ & 1.7 \\
\hline $\mathrm{Mg}$ & 0 & 0 & $0.20-0.85$ & $0.48-0.82$ & 14.79 \\
\hline $\mathrm{Na}$ & 0 & 0 & 0 & 0 & 0.48 \\
\hline $\mathrm{C}$ & 0 & 0 & 0 & 0 & 0 \\
\hline $\mathrm{Cl}$ & 0 & 0 & 0 & 0 & 0 \\
\hline
\end{tabular}

Wear testing with steatite plates as antagonists superficially polished the respective specimens. Grain boundaries of sintered specimens partly disappeared and were smeared. The formation of adhering clusters of worn steatite was observed, in particular on ground surfaces of both zirconia materials. Polished and worn zirconia specimens showed a stepwise smoothening of surfaces, partly covered by smeared wear debris. Some deep grinding grooves persisted.

Despite higher roughness values, SEM images of the sintered reference series showed grain structures similar to those of other sintered specimens with lower roughness values.

\subsection{EDX analysis}

SEM observations of material transfer from the steatite antagonists to the zirconia specimens were verified by EDX analysis. The EDX spectra showed that the steatite surface was composed of $\mathrm{Si}, \mathrm{Mg}, \mathrm{O}, \mathrm{Na}$, and $\mathrm{Al}$. Zirconia surfaces showed an elemental composition of $\mathrm{Zr}, \mathrm{O}, \mathrm{Y}, \mathrm{Si}, \mathrm{Hf}$, and $\mathrm{Al}$ before wear testing that was verified for all specimens after the different surface treatments. Because the surfaces of all specimens were free of $\mathrm{Mg}$ before wear testing and steatite showed a high percentage (Wt\%) of $\mathrm{Mg}$ (Table 2), we investigated a potential transfer of magnesium from the antagonists to the specimens. Worn zirconia specimens showed an $\mathrm{Mg}$ content of up to $0.85 \mathrm{Wt} \%$ for both zirconia materials. Elements found both on steatite and zirconia specimens $(\mathrm{O}, \mathrm{Si}, \mathrm{Al})$ showed high deviations in $\mathrm{Wt} \%$.

\subsection{XRD analysis}

Representative XRD patterns of zirconia are shown in Fig. 2. Monoclinic peaks with an orientation to $\mathrm{m}(11-1)$ were detected for all zirconia specimens after the grinding and polishing procedures. Sintered specimens, including the reference specimens, did not show any monoclinic peaks, neither before nor after wear testing. The maximum intensity ratios between the $\mathrm{m}(11-1)$ peaks and the $\mathrm{t}\left(\begin{array}{ll}1 & 1\end{array}\right)$ peaks are

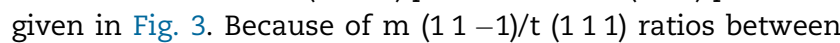
0.049 and 0.091 , grinding and polishing procedures were shown to induce tetragonal to monoclinic phase transformation. The final polishing step decreased the monoclinic phase share in all groups again. The lowest $\mathrm{m} / \mathrm{t}$ ratio was found after polishing step 3 for Cercon ht before and after wear testing and for Cercon base after wear testing. Almost no difference was found after polishing steps 2 and 3 for Cercon base before wear testing. Independent of the surface treatments applied, wear testing did not have any distinct influence on the phase transformation rates of specimens.

Compared to the sintered state, all grinding and polishing procedures showed a decrease and asymmetrical broadening of the $t\left(\begin{array}{lll}1 & 1 & 1\end{array}\right)$ peak combined with an increase in the FWHM of this peak (Table 3). Despite of variations in the FWHM within the different groups, both zirconia materials, with or without wear simulation, showed a decreased FWHM after the third polishing step. All surface treatments (grinding and polishing)

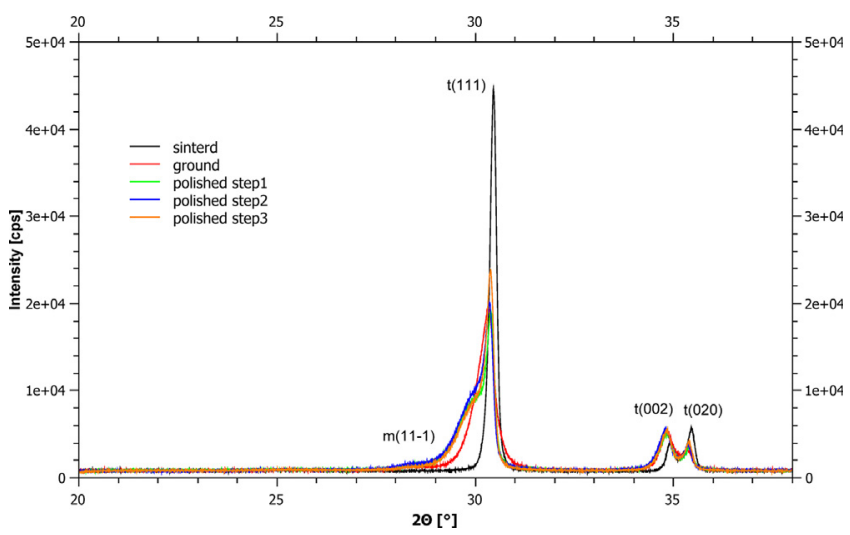

Fig. 2 - XRD patterns of zirconia after different surface treatments (example: Cercon ht before wear testing).

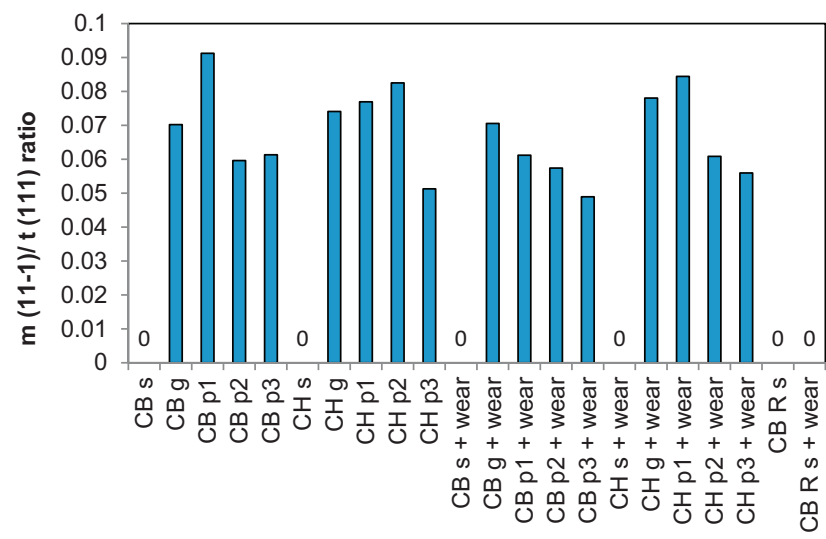

Fig. 3 - Maximum intensity ratios $m\left(\begin{array}{lll}1 & 1 & -1\end{array}\right) / t\left(\begin{array}{lll}1 & 1 & 1\end{array}\right)$ of the zirconia specimens (Cercon base: $\mathrm{CB}$, Cercon ht: $\mathrm{CH}$, Reference: R) with different surface treatments before and after wear testing: sintering (s), grinding (g), polishing step 1 (p1), step 2 (p2), step 3 (p3). 
Table 3 - FWHM (full width at half maximum) of the $t$ (1 11 1) peak.

\begin{tabular}{lcccc} 
FWHM of t $(11)$ peak $\left(^{\circ}\right)$ & Cercon base & Cercon ht & Cercon base + wear & Cercon ht + wear \\
\hline Sintered & 0.179 & 0.201 & 0.193 & 0.244 \\
Ground & 0.473 & 0.518 & 0.506 & 0.484 \\
Polished step 1 & 0.721 & 0.427 & 0.337 & 0.604 \\
Polished step 2 & 0.360 & 0.423 & 0.330 & 0.337 \\
Polished step 3 & 0.337 & 0.290 & 0.329 & 0.314 \\
\hline
\end{tabular}

led to a reversal of intensities of the tetragonal peaks $t\left(\begin{array}{ll}0 & 0\end{array}\right)$ and $t\left(\begin{array}{ll}0 & 2\end{array}\right)$. The intensity ratio between the $t\left(\begin{array}{lll}0 & 0 & 2\end{array}\right)$ and the $t$ (0 2 0) peak was about 0.7 for sintered specimens, but 1.2-1.7 after surface manipulation.

\section{Discussion}

This study confirmed the part of the hypothesis that surface roughness and phase transformation are influenced by dental adjustment procedures (grinding and polishing). With regard to wear testing, the hypothesis was rejected because wear had only a marginal influence on roughness and no influence on phase transformation.

Grinding resulted in rough and grooved zirconia surfaces. Subsequent polishing steps reduced such surface roughness. The final surface roughness $R_{a}$ value after the completion of all polishing steps was about $0.2 \mu \mathrm{m}$ for both zirconia materials, and this value is similar or even less than that reported for glaze layers. ${ }^{9,13}$ With regard to roughness, the use of a zirconia polishing kit may be a reasonable and time-saving alternative method to re-glazing. Nevertheless, even longer polishing times may be necessary to completely remove deep grinding grooves. Thus, hard zirconia surfaces need to be polished accurately without omitting any of the polishing steps.

High-gloss zirconia becomes even more important as a dental material when applied in full-contour restorations because smooth zirconia surfaces cause less wear of antagonistic enamel than conventional veneering ceramics. ${ }^{9,14,15}$ In contrast to polished zirconia, rough zirconia might continuously damage the antagonistic tooth in the long term.

The comparably high decrease in roughness values for ground surfaces after wear testing was mainly caused by deep grooves filled with wear debris of the antagonist. Accordingly, SEM images showed zirconia surfaces smeared with wear debris and adhering clusters of worn steatite. This phenomenon was more pronounced in ground surfaces but was also observed in sintered and polished zirconia specimens. EDX analysis verified this material transfer from steatite that is composed of multi-component crystalline phases of magnesium-aluminium-silicate. ${ }^{16}$ As an antagonistic material, steatite may not be an ideal substituent for human enamel because of its differing mechanical and tribological properties, such as higher hardness (steatite: $680 \mathrm{HV}$; enamel: $330 \mathrm{HV})^{17}$ or initial roughness (steatite: $1.7 \pm 0.2 \mu \mathrm{m}$; enamel: $0.9 \pm 0.2 \mu \mathrm{m})^{10}$ but it allows the standardization of antagonistic conditions.

Furthermore, many other factors are expected to contribute to the complexity of the wear process. Wear in general is a consequence of the interaction between surfaces moving in contact, causing the gradual removal of material. ${ }^{18}$ Influencing factors are the abrasive nature of food, the properties of the antagonist material, and the individual chewing behaviour combined with parafunctional habits and neuromuscular forces. ${ }^{18-20}$ The underlining tribological mechanisms include abrasive, adhesive, fatigue, and corrosive wear. ${ }^{18,21}$ Undoubtedly, clinical tests are essential for estimating the complex wear, grinding, and polishing performance of dental materials. However, such in vivo evaluations are often restricted by high costs and coincide with high variability amongst patients because individual chewing forces or ambient conditions cannot be sufficiently controlled. ${ }^{22,23}$ In contrast, in vitro studies may not only allow the investigation of single parameters of the adjustment and wear process but also a comparative evaluation of different materials under standardized conditions. However, even in vitro wear simulations show considerable variability. ${ }^{24}$

Because of their superior mechanical properties, yttriastabilized tetragonal zirconia polycrystals (Y-TZP) seem to be predestined as a substructure material for fixed partial dentures (FPDs) and full-contour restorations in posterior areas. ${ }^{25}$ The increased fracture toughness of Y-TZP may be explained by phase transformation from the tetragonal to the monoclinic phase upon external application of stress accompanied by a $3-5 \%$ increase in volume. ${ }^{7}$ The associated development of local compressive stress closes crack tips and prevents further propagation. As a consequence of chairside surface manipulations, superficial phase transformations may occur and zirconia may prematurely lose this crack-stopping effect.

Calculations of the $\mathrm{m}\left(\begin{array}{lll}1 & 1 & -1\end{array}\right) / \mathrm{t}\left(\begin{array}{lll}1 & 1 & 1\end{array}\right)$ ratios of the maximal peak intensities in the XRD results allowed a comparison of the extent of superficial phase transformation after different surface treatments without calculating the exact volume fractions. This ratio was shown to be independent of timedependent absolute intensity variations that were related to the cathode in the X-ray tube. In former studies, the $t \rightarrow \mathrm{m}$ phase transformation was characterized by various methods, for example by XRD, ${ }^{2,4,12,26,27}$ Raman spectroscopy, ${ }^{28,29}$ and scanning powder-diffraction-based contrast tomography ( $\mu$ CT-XRD). ${ }^{3}$ Calculated intensities and volume fractions strongly depend on the method of measurement and do not allow any direct comparisons. The penetration depth affects the relative amount of the monoclinic signal. ${ }^{3}$ For the applied XRD analysis, signals originated from a penetration depth of $1-3 \mu \mathrm{m} .{ }^{30}$ Only the combination of different methods may allow the comprehensive characterization of the transformed zone. Therefore, in the present study, we focused on investigating the $m\left(\begin{array}{llll}1 & 1 & -1\end{array}\right) / t\left(\begin{array}{lll}1 & 1 & 1\end{array}\right)$ ratio instead of reporting the exact volume fractions. In previous studies, ${ }^{2,3,31}$ volume fractions of the monoclinic phase after grinding, polishing, or diamond-cutting were reported to be lower than $5-10 \%$. Although no direct comparisons to the volume fractions of these studies are possible, the present $\mathrm{m} / \mathrm{t}$ ratios between 0.049 and 0.091 indicate low phase 
transformation rates and may be seen as an appropriate evaluation method of the $\mathrm{t} \rightarrow \mathrm{m}$ transformation.

No monoclinic phases were found on the surface of any of the sintered specimens. Wear testing did not induce any phase transformation of these specimens. Sintered reference specimens with high $R_{a}$ values showed that the $m\left(\begin{array}{lll}1 & 1 & -1) / t\end{array}\right)\left(\begin{array}{lll}1 & 1 & 1\end{array}\right)$ ratio was independent of surface roughness. Although the $\mathrm{m} / \mathrm{t}$ ratio varies within the first polishing steps and grinding, a trend to lowest values was found after the completion of all polishing steps, both with or without wear simulation. This finding underlines the importance of careful polishing without omitting any polishing steps. A reason for the varying $\mathrm{m} / \mathrm{t}$ ratios in the preceding steps may be some retransformation from the monoclinic to the tetragonal phase, resulting from the low thermal conductivity of zirconia and local heating during manipulation. ${ }^{32,33}$ A further reason may be the presence of deep grinding grooves that were not reached by all treatment steps. The variability of this ratio was also observed for specimens after wear testing. However, phase transformation is not supposed to be induced by wear but rather by the previous surface treatments because worn sintered specimens did not show any phase transformation. Nevertheless, the applied wear assay may be viewed as gentle wear testing. Other wear assays (e.g. pin-on-block or threebody wear) in combination with higher force impacts and different environmental conditions (e.g. food bolus) may show different results and cause phase transformation.

The broadening of the tetragonal peak after surface manipulation may be explained by a strained tetragonal structure because one of the influencing factors of the FWHM is lattice strain. This assumption would be consistent with the reduction in the FWHM and the decrease in the $\mathrm{m} / \mathrm{t}$ ratio after completion of all polishing steps. An increase in the FWHM with sandblasting followed by a decrease during the veneering simulation was described by Hallmann. ${ }^{12}$ Accordingly, the phase transformation after grinding was described as successfully reversed by annealing. ${ }^{34}$ Although lattice distortion is seen as the most probable reason for the observed broadening of the tetragonal peak, a further explanation may be the formation of a new phase (rhombohedral or cubic). ${ }^{11,34}$ However, the presence of an additional phase could not be inferred from the present XRD patterns. A reversal of the intensities of the tetragonal peaks $t\left(\begin{array}{lll}0 & 0\end{array}\right)$ and $t\left(\begin{array}{lll}0 & 2 & 0\end{array}\right)$ after surface manipulations may be explained by ferroelastic domain switching. ${ }^{35}$

The results of this study apply to two zirconia materials provided by the same manufacturer. Different zirconia materials show similar composition but may differ in sintering temperature and resulting grain sizes. Particularly sintering conditions may influence microstructure, longevity, hydrolytic performance, and finally wear. A small grain size may impair tetragonal to monoclinic transition, and small amounts of $\mathrm{Al}_{2} \mathrm{O}_{3}$ improve corrosion stability. Therefore, further investigations with different zirconia materials are recommended.

\section{Conclusions}

Within the limitations of this study and the fact that only the zirconia material of one manufacturer was used, we may conclude that careful polishing including all polishing steps reduced the surface roughness of ground zirconia. The $\mathrm{m} / \mathrm{t}$ ratios indicated the lowest phase transformation rates after the final polishing step. Wear was shown to have minor influence on roughness and no influence on phase transformation but resulted in material transfer from antagonists. In clinical application, zirconia should be polished according to the instructions of the manufacturer to keep values for surface roughness and phase transformation as low as possible.

\section{R E F E R E N C E S}

1. Etman MK, Woolford MJ, Dunne S. Quantitative measurement of tooth and ceramic wear: in vivo study. International Journal of Prosthodontics 2008;21:245-52.

2. Karakoca S, Yilmaz H. Influence of surface treatments on surface roughness, phase transformation, and biaxial flexural strength of Y-TZP ceramics. Journal of Biomedical Materials Research Part B: Applied Biomaterials 2009;91:930-7.

3. Mochales C, Maerten A, Rack A, Cloetens P, Mueller WD, Zaslansky P, et al. Monoclinic phase transformations of zirconia-based dental prostheses, induced by clinically practised surface manipulations. Acta Biomaterialia 2011;7: 2994-3002.

4. Maerten A, Zaslansky P, Mochales C, Traykova T, Mueller WD, Fratzl P, et al. Characterizing the transformation near indents and cracks in clinically used dental yttria-stabilized zirconium oxide constructs. Dental Materials 2013;29:241-51.

5. Aboushelib MN, Wang $\mathrm{H}$. Effect of surface treatment on flexural strength of zirconia bars. Journal of Prosthetic Dentistry 2010;104:98-104.

6. Luthardt RG, Holzhuter MS, Sandkuhl O, Herold V, Schnapp JD, Kuhlisch E, et al. Reliability and properties of ground YTZP-zirconia ceramics. Journal of Dental Research 2002;81: 487-91.

7. Vagkopoulou T, Koutayas SO, Koidis P, Strub JR. Zirconia in dentistry: Part 1. Discovering the nature of an upcoming bioceramic. European Journal of Esthetic Dentistry 2009;4: 130-51.

8. Oh WS, De Long R, Anusavice KJ. Factors affecting enamel and ceramic wear: a literature review. Journal of Prosthetic Dentistry 2002;87:451-9.

9. Preis V, Behr M, Handel G, Schneider-Feyrer S, Hahnel S, Rosentritt M. Wear performance of dental ceramics after grinding and polishing treatments. Journal of the Mechanical Behavior of Biomedical Materials 2012;10:13-22.

10. Preis V, Behr M, Kolbeck C, Hahnel S, Handel G, Rosentritt M. Wear performance of substructure ceramics and veneering porcelains. Dental Materials 2011;27:796-804.

11. Cattani Lorente M, Scherrer SS, Richard J, Demellayer R, Amez-Droz M, Wiskott HWA. Surface roughness and EDS characterization of a Y-TZP dental ceramic treated with the CoJet $^{\text {TM }}$ Sand. Dental Materials 2010;26:1035-42.

12. Hallmann L, Ulmer P, Reusser E, Hämmerle CHF. Effect of blasting pressure, abrasive particle size and grade on phase transformation and morphological change of dental zirconia surface. Surface and Coatings Technology 2012;206: 4293-302.

13. Wang F, Chen J, Wang H. Surface roughness of a novel dental porcelain following different polishing procedures. International Journal of Prosthodontics 2009;22:178-80.

14. Stawarczyk B, Ozcan M, Schmutz F, Trottmann A, Roos M, Hämmerle CHF. Two-body wear of monolithic, veneered and glazed zirconia and their corresponding enamel antagonists. Acta Odontologica Scandinavica 2013;71:102-12. 
15. Janyavula S, Lawson N, Cakir D, Beck P, Ramp LC, Burgess JO. The wear of polished and glazed zirconia against enamel. Journal of Prosthetic Dentistry 2013;109: 22-9.

16. Krejci I, Albert P, Lutz F. The influence of antagonist standardization on wear. Journal of Dental Research 1999;78: 713-9.

17. Shortall AC, Hu XQ, Marquis PM. Potential countersample materials for in vitro simulation wear testing. Dental Materials 2002;18:246-54.

18. Mair LH, Stolarski TA, Vowles RW, Lloyd CH. Wear: mechanisms, manifestations and measurement. Report of a workshop. Journal of Dentistry 1996;24:141-8.

19. Johansson A, Kiliaridis S, Haraldson T, Omar R, Carlsson GE. Covariation of some factors associated with occlusal tooth wear in a selected high-wear sample. Scandinavian Journal of Dental Research 1993;101:398-406.

20. Kim SK, Kim KN, Chang IT, Heo SJ. A study of the effects of chewing patterns on occlusal wear. Journal of Oral Rehabilitation 2001;28:1048-55.

21. Mair LH. Wear in dentistry - current terminology. Journal of Dentistry 1992;20:140-4.

22. Condon JR, Ferracane JL. In vitro wear of composite with varied cure, filler level, and filler treatment. Journal of Dental Research 1997;76:1405-11.

23. Hickel R, Roulet JF, Bayne S, Heintze SD, Mjör IA, Peters M, et al. Recommendations for conducting controlled clinical studies of dental restorative materials. Clinical Oral Investigations 2007;11:5-33.

24. Heintze SD. How to qualify and validate wear simulation devices and methods. Dental Materials 2006;22:712-34.

25. Al-Amleh B, Lyons K, Swain MV. Clinical trials in zirconia: a systematic review. Journal of Oral Rehabilitation 2010;37: 641-52.
26. Allahkarami M, Hanan JC. Mapping the tetragonal to monoclinic phase transformation in zirconia core dental crowns. Dental Materials 2011;27:1279-84.

27. Guazzato M, Albakry M, Ringer SP, Swain MV. Strength, fracture toughness and microstructure of a selection of allceramic materials. Part II. Zirconia-based dental ceramics. Dental Materials 2004;20:449-56.

28. Chintapalli RK, Marro FG, Jimenez-Pique E, Anglada M. Phase transformation and subsurface damage in 3Y-TZP after sandblasting. Dental Materials 2013;29:566-72.

29. Ozcan M, Melo RM, Souza ROA, Machado JPB, Felipe Valandro L, Botttino MA. Effect of air-particle abrasion protocols on the biaxial flexural strength, surface characteristics and phase transformation of zirconia after cyclic loading. Journal of the Mechanical Behavior of Biomedical Materials 2013;20:19-28.

30. Cullity BD. Elements of X-ray diffraction. Reading, MA: Addison-Wesley Pub. Co.; 1956.

31. Kosmac T, Oblak C, Jevnikar P, Funduk N, Marion L. Strength and reliability of surface treated Y-TZP dental ceramics. Journal of Biomedical Materials Research 2000;53:304-13.

32. Juy A, Anglada M. Surface phase transformation during grinding of Y-TZP. Journal of the American Ceramic Society 2007;90:2618-21.

33. Annamalai VE, Sornakumar T, Gokularathnam CV, Krishnamurthy R. Transformations during grinding of ceriastabilized tetragonal zirconia polycrystals. Journal of the American Ceramic Society 1992;75:2559-64.

34. Denry IL, Holloway JA. Microstructural and crystallographic surface changes after grinding zirconia-based dental ceramics. Journal of Biomedical Materials Research Part B: Applied Biomaterials 2006;76:440-8.

35. Mehta K, Jue JF, Virkar AV. Grinding-induced texture in ferroelastic tetragonal zirconia. Journal of the American Ceramic Society 1990;73:1777-9. 